\title{
Elimination of polluting nutrients from wastewater
}

\author{
Nina Zaletova* \\ Moscow State University of Civil Engineering, Yaroslavskoe shosse, 26, Moscow, 129337, Russia
}

\begin{abstract}
Results of long time of experiments of phosphorus and nitrogen removal technology from municipal wastewater conducted in laboratory and on few pilot industrial plants are described. Peculiarities of chemical method of phosphorus removal and advantages of biological method of phosphorus removal, including further utilisation of phosphorus as a fertiliser are observed. New approach for nitrogen removal, based on usage of immobilised microorganisms is discussed
\end{abstract}

\section{Introduction}

The most popular method of municipal wastewater treatment in Russia is traditional biological method. This method allows removing suspended and organic matters, but does not provide sufficient nitrogen and phosphorus elimination. According to the modern regulations for treated municipal wastewater permissible concentrations of phosphates -0.2 $\mathrm{mg} / \mathrm{l}$, nitrates - $9.1 \mathrm{mg} / \mathrm{l}$, nitrites - $0.02 \mathrm{mg} / \mathrm{l}$, ammonium - $0.39 \mathrm{mg} / \mathrm{l}$. It means that efficiency of removal of these compounds must exceed $70-90 \%$. On this reason during several years, experiments have been conducted to identify methods of nitrogen and phosphorus removal.

\section{Materials and methods}

Chemical phosphorus removal. This method is widely used in Western Europe and the USA. Phosphorus removal occurs due to formation of non-soluble phosphorus compounds with metal ions, further come into activated sludge. Taking into consideration standards for concentration impurities of treated wastewater, we focused our efforts on investigation of technological parameters of biological treatment biological treatment with additional introduction reagents that can meet installed regulations for treated wastewater. Three technological schemes were studied (Fig. 1). Two of them (scheme 1 and scheme 2) based on introduction of reagent during biological treatment and scheme 3 based on introduction of reagent before filter.

The investigations carried out on pilot plant with capacity of $24 \mathrm{~m}^{3} /$ day and experimental industrial wastewater treatment plant in Tichvin town (Leningrad region) with

\footnotetext{
*corresponding author: naz1604@yandex.ru
} 
capacity 5000m3/day. The pilot plant consisted of aeration tank and vertical type secondary clarifier.

Aeration tank has been equipped with diffuser units for air feeding. Special basin was used for preparation of reagent solution. Reagent solution supplied by a dose-pump. Wastewater delivered to the plant with permanent flow. Scheme of treatment included grit chamber, two primary clarifiers $(\mathrm{d}=10 \mathrm{~m})$, one aeration tank $\left(\mathrm{V}=985 \mathrm{~m}^{3}\right)$, four secondary clarifiers $(\mathrm{d}=10 \mathrm{~m})$ and a basin for preparation of reagent solution. All experiments were done with real municipal wastewater. The basic characteristic of composition of pollutants in wastewaters is given in Table 1.

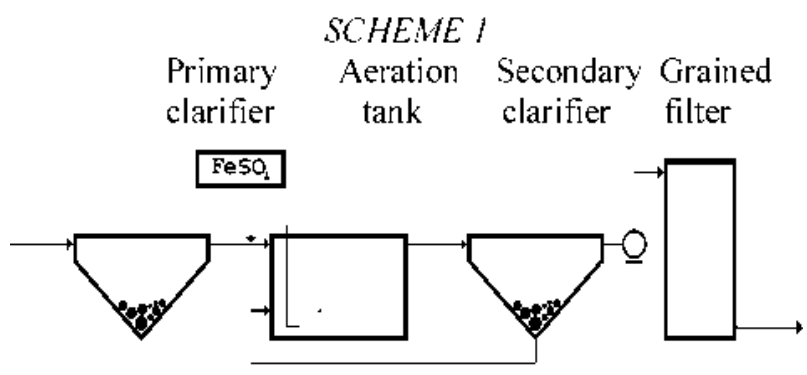

Concentration, $\mathrm{mg} / \mathrm{l}$

BOD

Suspended solids

Total phosphorus
150.0
120.0
18.0

$\begin{array}{ll}10.0 & 3.5 \\ 10.0 & 2.0 \\ 2.4 & 2.0\end{array}$

$S C H E M E 2$

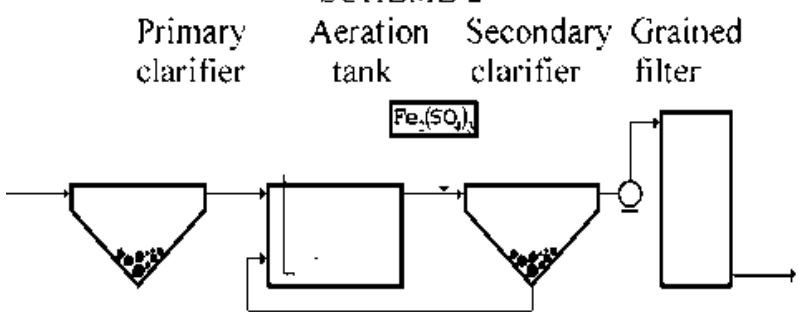

Concentration, $\mathrm{mg} / \mathrm{l}$

BOD

Suspended solids

Total phosphorus

$\begin{array}{lll}150.0 & 10.0 & 3.5 \\ 120.0 & 10.0 & 2.0 \\ 18.0 & 2.4 & 2.0\end{array}$

SCHEME 3

Primary Aeration Secondary Grained

clarifier tank clarifier filter

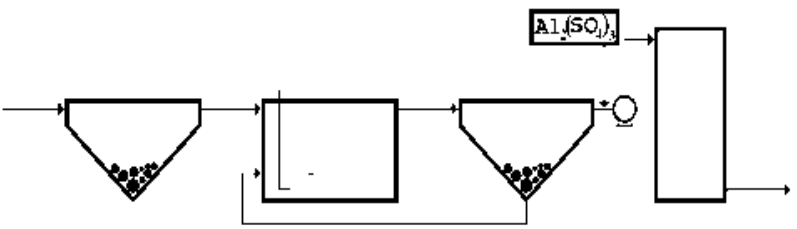

Concentration, $\mathrm{mg} / 1$

BOD

Suspended solids

Total phosphorus
150.0

120.0

18.0
10.0

10.0

3.0
1.0

1.0

1.0

Fig. 1. Studied schemes of treatment 
Technological parameters of running of experimental plants are indicated in Table 2. The following conclusions can be done on the base of received experimental data. Required reagent dose should be increased at higher requirements to the quality of treated water, higher initial quantity of phosphorus or heavily contaminated wastewater in general. Introduction of reagent into aeration tank can lead to certain effects for the process of biological treatment.

Table 1. Characteristic of wastewater flow coming for biological-chemical treatment

\begin{tabular}{|c|c|c|c|c|c|c|}
\hline \multirow{2}{*}{ INGR. } & \multicolumn{6}{|c|}{ CONCENTRATION, mg/l } \\
\cline { 2 - 7 } & \multicolumn{3}{|c|}{ Pilot plant } & \multicolumn{3}{c|}{ Industrial plant } \\
\cline { 2 - 7 } & $\min$ & $\max$ & mid & $\min$ & $\max$ & mid \\
\hline BOD & 60.0 & 120.0 & 95.0 & 65.0 & 114.0 & 105.0 \\
\hline $\mathrm{COD}$ & 170.0 & 250.0 & 230.0 & 178.0 & 300.0 & 432.0 \\
\hline $\mathrm{SS}$ & 66.0 & 188.0 & 160.0 & 155.0 & 290.0 & 230.0 \\
\hline $\mathrm{N}_{\text {tot }}$ & 20.0 & 38.0 & 35.0 & 20.0 & 30.0 & 26.5 \\
\hline $\mathrm{NH} 4$ & 17.0 & 35.0 & 27.0 & 11.9 & 15.7 & 14.0 \\
\hline $\mathrm{NO} 3$ & 0.4 & 1.1 & 0.9 & 0.64 & 2.3 & 1.62 \\
\hline $\mathrm{P}_{\text {tot }}$ & 3.2 & 5.2 & 4.6 & 4.5 & 8.6 & 6.4 \\
\hline PO4 & 1.6 & 2.1 & 1.7 & 2.2 & 5.7 & 4.1 \\
\hline
\end{tabular}

Table 2. Technological parameters

\begin{tabular}{|c|c|c|c|c|}
\hline Type of plant & $\begin{array}{c}\text { MLSS, } \\
\text { g/l }\end{array}$ & $\begin{array}{c}\text { Treating load, } \\
\text { mgBOD/(g day })\end{array}$ & Reagent & $\begin{array}{c}\text { Dose of reagent, } \\
\mathrm{mg} / \mathrm{l}\end{array}$ \\
\hline Pilot plant & $1.5-7.0$ & $200-600$ & $\mathrm{FeSO}_{4}$ & $10-40$ \\
& $1.0-5.0$ & $200-400$ & $\mathrm{Fe}_{2}\left(\mathrm{SO}_{4}\right)_{3}$ & $5-25$ \\
\hline Industrial plant & $2.0-4.0$ & 100 & $\mathrm{Al}_{2}\left(\mathrm{SO}_{4}\right)_{3}$ & $5-25$ \\
\hline
\end{tabular}

Addition of reagent can either intensify or inhibit the process of biological treatment. Impact force depends upon the dose of added reagent $\left(\mathrm{A}_{\text {reag. }}\right.$., $\left.\mathrm{mg} / \mathrm{l}\right)$ and the dose of volatile sludge (MLVSS, g/l) in aeration tank. This effect was named as reagent loading to the sludge $\left(\mathrm{N}_{\text {reag. }}, \mathrm{mg} / \mathrm{g}\right)$. Intensification (or inhibition) of the biological-chemical process initiates increasing (or lowering) specific rate of oxidation of organic matters ( $\rho$, $\mathrm{mgBOD} /(\mathrm{g}$ MLVSS day)). Correlation between reagent loading and changes of specific rate of oxidation of organic matters (that is ratio $\rho$ for biological-chemical and $\rho$ for biological process) is given in Fig. 2.

During the experiments the maximum value of allowed dose of reagent was determined. The investigations showed that addition of reagent alters the properties of sludge. In all cases it was indicated increasing of dewatering capability of sludge, which is undoubtedly positively for further sludge treatment. It was indicated that the addition of ferrous sulphate into aeration tank has caused lowering of sludge index, but introduction of ferric sulphate before secondary clarifier increased sludge index up to swelled activated sludge in some cases. Due to increasing of concentration of suspended solids in treated wastewater grows concentration of ions of metals in treated water. That is why in this case, it was recommended to take special measures to avoid ion metals in effluent, such as: reducing of added dose of reagent, introduction of polyelectrolyte for better sludge floc formation, including in treatment scheme cleaning filters

In the case of introduction of reagents before filters as it is shown on the scheme 3 it is possible to apply only filters with higher mud capacity. To avoid remaining ion metals concentrations in treated water it is necessary to take the following measures: to reduce filtration rate (compared with the scheme without the use of a reagent), to increase number of filter washes, to introduce an additional layer of fine grain filter bed. In spite of several advantages of simultaneous utilisation of chemical and biological treatment of wastewater such as rapid effect of phosphorus removal, reliable quality of treated water, possibility to 
use the treatment in running treatment plants without considerable changes in technological process, this technology did not find broad practical application in Russia now. The main barrier for wide application of such technology is rather huge quantity of chemicals to be supplied to waste water treatment plants.

Biological phosphorus removal. Selected for investigation technology of biological phosphorus removal based on the ability of activated sludge to consume phosphate actively in aerobic conditions after treatment of recirculated activated sludge in anaerobic conditions, where phosphates are released from sludge to liquid phase.

Scheme with deep phosphorus removal includes treatment of wastewater in installations of traditional biological treatment, which is in primary clarifier, aeration tank and secondary clarifier. Phosphorus release from recirculated activated sludge takes place in special additional installation like secondary clarifier. In the scheme internal flow of wastewater with rather high phosphate concentration is formed. The most suitable reagent for phosphorus removal from this flow is lime. In this case P-Ca-containing sludge is formed. This sludge includes two main elements of mineral fertiliser, which are used for soil fertilisation and raising its alkalinity. That is why when biological phosphorus removal is used there are two tasks can be solved such as deep phosphorus removal without using of reagent in the main treatment installations, as well as producing of additional product fertiliser.

Considering saying above the task was to investigate technological parameters of process of biological phosphorus removal as well as to produce and appreciate advisability of using of P-Ca-containing sludge as fertiliser Studies were conducted several years. The fulfilled scientific work can be divided on the following five stages:

1 - laboratory investigations in contact conditions;

2 - investigations in semi-periodical conditions. In this case activated sludge constantly presented in biological system and passed through all necessary stages of treatment but treated wastewater was added in installation periodically;

3 - investigations on a pilot plant. The capacity of the plant was $24 \mathrm{~m}^{3} /$ day. Scheme of the installation was the same as principal scheme of the process;

4 - full scale investigations on industrial plant - on aeration station of Tichvin. Experimental plant was reconstructed according to developed technology. Two secondary clarifiers were re-equipped in installations for P-realiser. Necessary volume of aeration tanks определен was defined. The capacity of the plant was $4500 \mathrm{~m}^{3} /$ day. Experimental plant was running during three years;

5 - agrochemical investigations of P-Ca-containing sludge for use as fertiliser.

Investigations were done in few stages. Each stage of experiments has been concentrated on study of certain processes of biological phosphorus removal. During laboratory experiments dynamic of phosphate release from sludge and some other characteristics was investigated. The results of the process are presented on Fig. 2.

As it obvious from data practically full phosphorus removal was reached. Concentration of phosphorus in influent was $2-3.5 \mathrm{mg} / \mathrm{l}$, but in decanted water - concentrations increased up to $7-16 \mathrm{mg} / \mathrm{l}$. This water flow was used for preparation experimental portion of fertilise.

The technological parameters of the process in flowing conditions on the pilot plant were studied as well. It was established that efficiency of process depends mainly on the time of release of phosphate in anaerobic conditions and organic loading. Achieved efficiency of removal of phosphorus was $75-85 \%$, dissolved phosphate - up to $95 \%$. Concentrations of matters in effluent were: BOD $12-15 \mathrm{mg} / \mathrm{l}$, phosphate $0.1-0.3 \mathrm{mg} / \mathrm{l}$, ammonium 17-19 mg/l, and nitrate 0.1-0.5 mg/l.

Experimental industrial plant in Tichvin has been running for three years in the regime of biological phosphorus removal. Data of phosphorus content in influent and effluent during this period are given in Fig. 3 . 


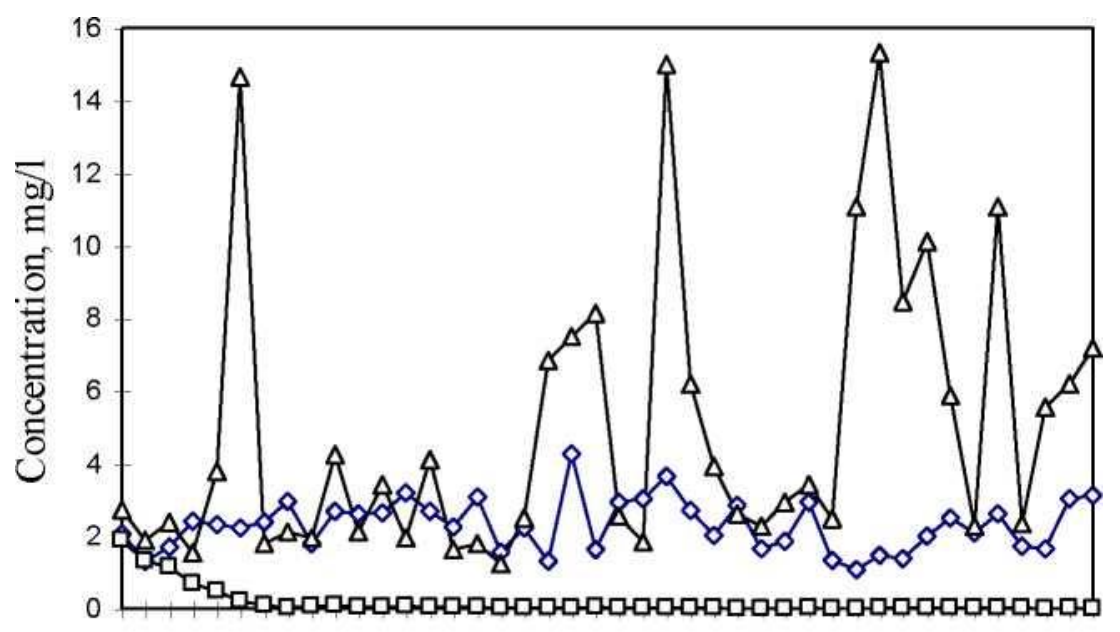

Days of experiment

Fig. 2. Concentration of phosphates in semi-periodical process

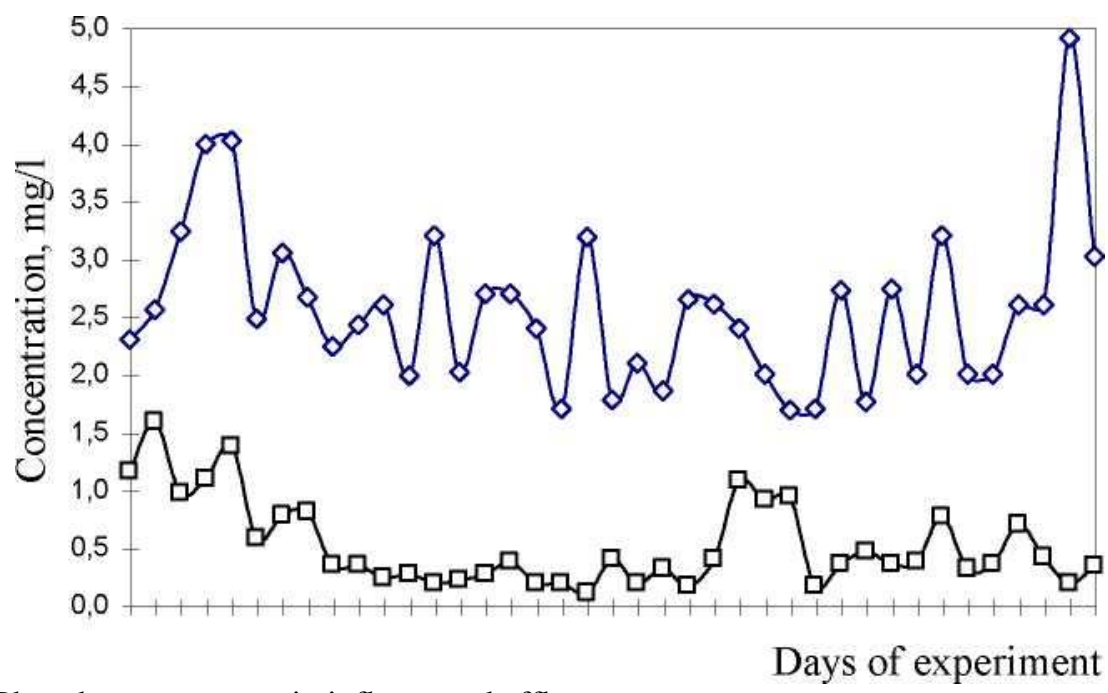

Fig. 3. Phosphorous content in influent and effluent

Data of experiment showed that efficiency of phosphorus removal had been very high continually. Quality of treated water was rather stable. Within this, it was pointed out good removal of some other types of contaminated matters. Treated water had the following characteristic: BOD 6 - 9 mg/l, COD 58 - $90 \mathrm{mg} / \mathrm{l}$, ammonium - 3.3 - $9.2 \mathrm{mg} / \mathrm{l}$, nitrates 3.3 $5.0 \mathrm{mg} / \mathrm{l}$.

Study of obtaining of fertiliser from decanted water with reach phosphorus content was done together with Russian Scientific Research Institute of Fertiliser. During the experiment lime dose was indicated under which phosphates were able to fall down as a sediment, but at the same time phosphates kept the form adapted by plants. In addition to the chemical analyses, agro-chemical tests with phosphorus-calcium sediment were done during vegetation period. Preliminary results of agro-chemical tests showed that the fertiliser was more effective for raps crop than standard lime. Efficiency of using of phosphorus-calcium containing sediment was equal efficiency of lime enriched with superphosphate. The fertiliser positively affected on agrochemical soil properties and facilitated phosphorus accumulation enough for plants. Results of tests for microelements 
of the fertiliser showed that it can be applied as microfertilizer. Wide application of biological technology of phosphorus removal from municipal wastewater and utilisation of phosphorus - calcium sediment will allow making further step to restore natural circulation of phosphorus.

Nitrogen removal technology. There are several methods of deep nitrogen removal from wastewater: physico-chemical method and biological one. The listed methods are differ with efficiency and areas of application. At present time throughout the world the prospective and more practical for huge volumes of municipal waste water to be treated is method of biological nitrification-denitrification. During nitrification, the oxidation of ammonium into nitrites and nitrates takes place. In the process of denitrification, oxidised forms of nitrogen were restored to nitrogen as gas. It is known that for more effective denitrification certain amount of organic matter is required. It was proved that utilisation of organic matters contented in wastewater to be treated is the most economical way for denitrification. To the present time several technological schemes of nitrificationdenitrification developed. Investigations were conducted on one - staged nitrogen removal and two - staged scheme with suspended activated sludge (Fig. 4).

ONE STAGE SCHEME

$\begin{array}{lll}\text { Primary } & \text { Denitri- Nitrifi } & \text { Secondary } \\ \text { clarifier } & \text { fication cation } & \text { clarifier }\end{array}$

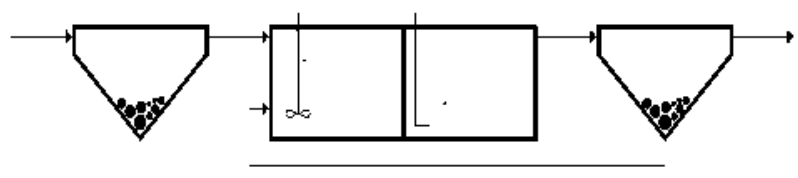

Recirculation $-400 \%$

TWO STAGES SCHEME $30 \%$

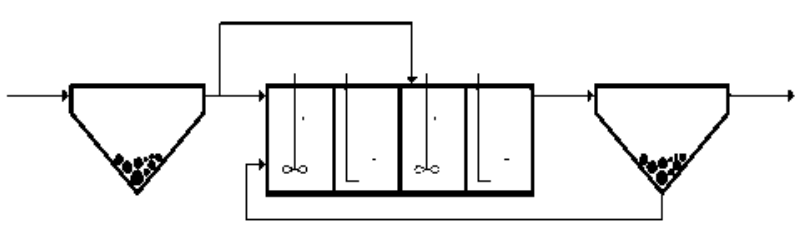

Recirculation - $100-200 \%$

Fig. 4. Schemes of biological nitrification-denitrification

The research work has been carried out on experimental unit with capacity of 10 $\mathrm{m}^{3} /$ day. For industrial researches, two-staged scheme has been chosen. As it was proved in laboratory-scale experiment, such a scheme was more effective. It provided more stable quality of treated water. Experiments were done during more than two years on industrial plant of Chelyabinsk (Ural area). Experimental plant (capacity of $8000-10000 \mathrm{~m}^{3} / \mathrm{day}$ ) included primary clarifier, denitrification tank of step 1, nitrification tank of step 1, denitrification tank of step 2, nitrification tank of step 2 and secondary clarifier. Wastewater treatment carried out on experimental plants provided reduction of BOD up to 6-8 $\mathrm{mg} / \mathrm{l}$, COD up to 50-60 mg/l. Variations of nitrogen content are given in Fig. 5. 


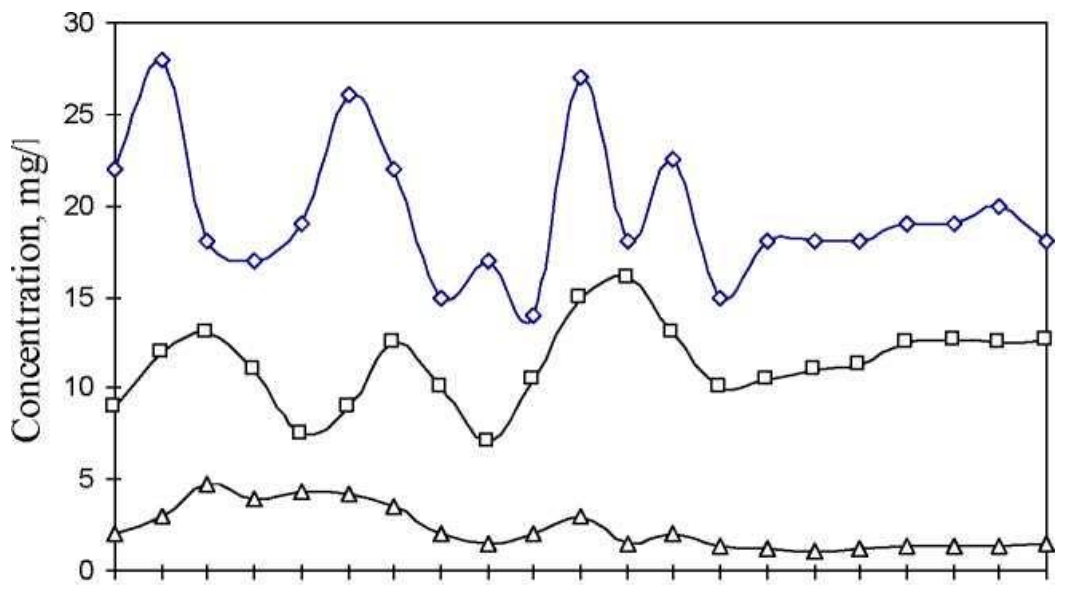

Days of experiment

Fig. 5. Variations of nitrogen content

Obviously, from these results that during waste water treatment ammonium concentration in inlet water has been reduced from $15-25 \mathrm{mg} / \mathrm{l}$ to $1.1-4.0 \mathrm{mg} / \mathrm{l}$ in treated water. Within this nitrate concentration in treated water has been variated from 8 to $12 \mathrm{mg} / \mathrm{l}$ (maximum was $15 \mathrm{mg} / \mathrm{l}$ ). Efficiency of total nitrogen removal was 50-60\%. Received experimental data and studies of scientific literature allowed to develop a mathematic model and applied program for PC destined for calculation of technological two stages schemes of nitrification- denitrification. Experiments and calculations showed that in spite of rather low content of organic matters in wastewater (which is very common for Russian towns) biological process of nitrification-denitrification would go during long time. That is why the technology would demand considerable capital and operational expenditure and large territories.

Technologies with immobilised microflora. There is a possibility to intensify the process of nitrification-denitrification by application of microflora, immobilised on inert carrier in aeration tank. Big range of synthetic and natural materials with different properties and structures allows choosing more relevant carrier for wastewater treatment plants and equipment.

It was developed several biological treatment technologies based on synthetic carriers in the form of cords and bits. There are following advantages of synthetic carriers - practically not wear out, not rotted, with large specific surface for settling of microorganisms, easy forming blocks of any configuration, simple in current operation. Block with synthetic carriers can be installed in new treatment plant as well as in already operating treatment plants. Investigation of technology of wastewater treatment with synthetic carriers were developed in contact conditions and flowing conditions on experimental unit. Experiments were produced on the base of real wastewater. One stage and two stage schemes were studied.

Microbiological experiments proved that even in aerobic conditions nitrified and denitrified microflora has been occurs on synthetic carrier. Due to this, efficiency of this technology is exceeding to similar technology with suspended microflora. Offered technology provides rather higher level of COD removal, deeper ammonium removal and total nitrogen removal, provides deep hydrolyse of total phosphorus. Very attractive results during application of bits of synthetic carrier due to rational utilisation of biofilm properties were obtained. For example- BOD 6 - 7mg/l, concentration ammonium 2 - $3 \mathrm{mg} / \mathrm{l}$, suspended 
solids - 3 - $7 \mathrm{mg} / \mathrm{l}$, total nitrogen - less than $15 \mathrm{mg} / \mathrm{l}$ or nearly $70 \%$ removal. It is necessary to point out that to obtain listed above quality parameters of treated wastewater it took 2-4 times less time, then during biological nitrification-denitrification with suspended activated sludge. The investigated technology of wastewater treatment can be used in newly build plants as well as on already operated.

For more deep removal of ammonium and organic matters, technology of biological tertiary treatment was elaborated. The technology operates on principle of dry filtration. Synthetic grain material has been used as filling material. Effect of biological treatment takes place due to immobilized microflora on surface grains.

\section{Conclusions}

Wide studies a number of technologies of phosphorous and nitrogen removal from municipal wastewaters were carried out on real wastewater on treatment plants in different parts of Russia.

Advanced technologies allow meet existing regulations for wastewater discharging in water body, established in Russia.

Studied technologies of nitrogen and phosphorus removal permit object to create a variety of technological schemes of sewage treatment from the nutrients.

There is strong evidence that new offered technologies will become prospective for large and small municipalities due to high efficiency of phosphorous and nitrogen removal. At the same time the application of the technologies, helps improve of waterbody's conditions in general.

\section{References}

1. Zaletova N. Water and sanitation, 9, 57-61 (2016)

2. Zaletova N. Nat. and tech. sci., 11-12, 383-386 (2014)

1. Zaletova N. Water and sanitation, 5-6, 20-23 (2014)

2. Yu. Yu. Lurie. Uniform methods of analysis of water. 1971

3. Condition indicators and tax rules for the fishery water objects. GOST 17.1.2.04-77. 1977

4. E.D. Babenkov. Water purification with coagulants. 1977.

5. I.L. Rabotnova. General Microbiology. 1982.

6. I.D. Rodziller. Forecast of the quality of receivers of wastewater. 1984

7. L.L. Rossolimo. Changes of limnological ecosystems 7 under the influence of anthropogenic factor. 1977

8. K. Y Kondratiev, I.S. Koplan-Diks. Evolution cycles of phosphorus and eutrophication of natural waters. 1988

9. The list of fishery regulations maximum allowable concentration (MACs) and approximately safe levels of exposure (EV) of harmful substances to water bodies of fishery value. VNIRO, 1999.

10. SP 32.13330/2012 Wastewater. External networks and constructions 2012

11. S.V. Zaletov. Removal of ammonium salt from municipal wastewater. $\mathrm{PhD}$ thesis. 1997.

12. EUROPEAN COMMUNITY COUNCIL DIRECTIVE of May 21, 1991 on urban wastewater treatment $(91 / 271 / \mathrm{EEC})$

13. Hermann H. Hahn, Rudolf Rlute. Chemical Water and Wastewater Treatment (Berlin. Springer-Verlag. 1990)

14. N. Zaletova, Y. Voronov, N.Makisha, Int. J. of Appl. Eng. Research, 10 (21) 4245442455 (2015) 